\title{
Management of Hepatitis C Post-liver Transplantation: a Comprehensive Review
}

\author{
Oscar Mitchell and Ahmet Gurakar* \\ Department of Transplant Hepatology, Division of Gastroenterology and Hepatology, Johns Hopkins University School of Medicine, \\ Baltimore, MD, USA
}

\begin{abstract}
Infection with hepatitis $\mathrm{C}$ virus (HCV) is a common cause of chronic liver disease, and HCV-related cirrhosis and hepatocellular carcinoma are the leading causes for liver transplantation in the Western world. Recurrent infection of the transplanted liver allograft is universal in patients with detectable HCV viremia at the time of transplant and can cause a spectrum of disease, ranging from asymptomatic chronic infection to an aggressive fibrosing cholestatic hepatitis. Recurrent HCV is more aggressive in the post-transplant population and is a leading cause of allograft loss, morbidity, and mortality. Historically, treatment of recurrent HCV has been limited by low rates of treatment success and high side effect profiles. Over the past few years, promising new therapies have emerged for the treatment of HCV that have high rates of sustained virological response without the need for interferon based regimens. In addition to being highly effective, these treatments have higher rates of adherence and a lower side effect profile. The purpose of this review is to summarize current therapies in recurrent HCV infection, to review the recent advances in therapy, and to highlight areas of ongoing research.

(C) 2015 The Second Affiliated Hospital of Chongqing Medical University. Published by XIA \& HE Publishing Ltd. All rights reserved.
\end{abstract}

\section{Introduction}

Infection with hepatitis $\mathrm{C}$ virus (HCV) is a cause of considerable morbidity and mortality. In 2011, an estimated 5.2 million people were living with $\mathrm{HCV}$ in the USA; and in

Keywords: Hepatitis C; Transplant; Directly acting antivirals.

Abbreviations: AASLD, American Association for the Study of Liver Diseases; ALC, absolute lymphocyte count; CNI, calcineurin inhibitors; COSMOS, Combination of SiMeprevir and sOfosbuvir in HCV genotype 1 infected patientS; CYP3A, cytochrome P3A; DAAs, direct acting antivirals; EASL, European Association for the Study of the Liver; $\mathrm{FCH}$, fibrosing cholestatic hepatitis; $\mathrm{HCV}$, hepatitis $\mathrm{C}$ virus: HVPG, hepatic venous portal pressure gradients; IDSA, Infectious Disease Society of America; IFN, interferon; IL-28B, interleukin-28B; NS3, nonstructural 3; PEG-IFN, pegylated interferon; QUEST, Quantitative Ultrasound Ezetimibe and Simvastatin Trial; RBV, ribavirin; RNA, ribonucleic acid; SVR, sustained virological response.

Received: 18 February 2015; Revised: 19 March 2015; Accepted: 22 March 2015 DOI: $10.14218 /$ JCTH.2015.00005.

*Correspondence to: Ahmet Gurakar, Department of Transplant Hepatology, Division of Gastroenterology and Hepatology, Johns Hopkins University School of Medicine, 720 Rutland Avenue, Ross Research Building \#918, Baltimore, MD 21205, USA. Tel: +1-410-614-2989, Fax: +1-410-614-9612, E-mail: aguraka1@ jhmi.edu
2007, HCV was responsible for over 15,000 deaths. ${ }^{1,2} \mathrm{HCV}$ is the leading indication for liver transplantation in the Western world and is a prominent cause for both hepatocellular carcinoma and liver cirrhosis worldwide. ${ }^{3-6} \mathrm{HCV}$ also carries a significant financial burden, with an estimated cost to the USA of $\$ 6.4$ billion, and a lifetime cost estimated between $\$ 64,490$ and as much as $\$ 270,000$ per patient. 7,8

Over the past few years, promising new therapies have emerged for the treatment of HCV that have demonstrated high rates of viral clearance without the need for interferon (IFN) based regimens. In addition to being highly effective, these treatments have higher rates of adherence and a lower side effect profile. These treatments have become the standard of care in the pretransplant setting and have an expanding role in the post-transplant setting. ${ }^{9,10}$ The purpose of this review is to summarize current therapies in recurrent HCV infection, to review the recent advances in therapy, and to highlight areas of ongoing research.

\section{$\mathrm{HCV}$ in the transplant recipient}

Recurrent infection of the transplanted liver is universal in patients with detectable HCV viremia at the time of transplant, and infection of the allograft occurs within hours of organ transplantation. ${ }^{11,12}$ Acute infection manifests in a significant proportion of patients $(62 \%$ in one study of 149 transplants) ${ }^{13}$ and is characterized by high viral titers, characteristic histological changes, and variable transaminitis. ${ }^{14}$ Diagnosis is histological, with biopsy showing lobular infiltrates, hepatocyte necrosis, and fatty infiltration. ${ }^{15}$ Viral clearance does not occur in recurrent HCV, and patients invariably progress to chronic infection. Severe recurrent HCV can manifest in two ways: as a chronic recurrent HCV infection and as an aggressive fibrosing cholestatic hepatitis $(\mathrm{FCH}) .{ }^{16}$

The course of chronic recurrent HCV in the immunocompromised transplant recipient is more aggressive than in immunocompetent patients, with 5 year rates of chronic hepatitis and cirrhosis reaching $80-95 \%$ and $10-28 \%$, respectively. ${ }^{14,17-21}$ Following the onset of cirrhosis, the risk for decompensation at 1 year is $42 \%$, and once decompensation occurs, the 1 year survival rate is as low as $41 \% .{ }^{18}$ As well as causing considerable morbidity and mortality, HCV recurrence puts further strain on the already scarce supply of donor livers; HCV is responsible for $27-41 \%$ of liver retransplantations. ${ }^{22,23}$

Although the majority of post-transplantation HCV manifests as chronic liver disease, a small proportion (10-12\%) of patients will develop $\mathrm{FCH}^{21,24}$ The diagnosis is made upon fulfillment of all of the following criteria: 1) Greater than 
1 month post-transplantation; 2) Serum bilirubin $>6 \mathrm{mg} / \mathrm{dL}$; 3) Serum alkaline phosphatase and gamma-glutamyltransferase level $>5$ times the upper limit of normal; 4) The presence of characteristic histology on biopsy (ballooning of hepatocytes, absence of inflammation, and cholangiolar proliferation without bile duct loss); 5) Very high serum HCV-ribonucleic acid (RNA) levels; and 6) Absence of surgical biliary complications and absence of evidence of hepatic artery thrombosis. ${ }^{16}$ The prognosis of cholestatic HCV is poor and typically results in rapid deterioration and death with or without liver transplant. ${ }^{16,25}$

\section{Risk factors for development of recurrent chronic HCV}

\section{Intrinsic recipient factors}

There are multiple intrinsic factors in liver allograft recipients associated with HCV recurrence. Levels of HCV viremia $\geq 1.0$ $\times 10^{6} \mathrm{vEq} / \mathrm{mL}$ prior to liver transplant were linked with significantly worse graft and patient survival (one study demonstrated RR of 4.3 and 3.6, respectively). ${ }^{19,26}$ High viral loads in the first 3 months post-transplant have also been associated with severity of $\mathrm{HCV}$ recurrence. ${ }^{21}$

Blasco et al. demonstrated that hepatic venous portal pressure gradients (HVPG) are good predictors of clinical decompensation due to HCV recurrence, with only $2 \%$ of patients with a normal HVPG and $67 \%$ of patients with abnormal HVPG progressing to decompensation. ${ }^{27} \mathrm{~A}$ recent study investigating absolute lymphocyte count (ALC) demonstrated that low ALC pretransplant and at 1 month post-transplant were significantly associated with $\mathrm{HCV}$ recurrence. ALC $<500 / \mu \mathrm{L}$ also negatively influenced both sustained virological response (SVR) rates and patient survival. ${ }^{28}$ Polymorphisms in interleukin-28B (IL-28B) were linked with recurrent HCV; recipients with the IL-28B $T T$ genotype were particularly at risk for severe histological recurrence of $\mathrm{HCV}^{29,30}$ Other recipient factors that have been associated with recurrent $\mathrm{HCV}$ severity include female sex, race, socioeconomic factors, and severity of disease. ${ }^{16,26,28,31-34}$

The link between cytomegalovirus infection and HCV recurrence remains unclear, with some studies showing an association between CMV and HCV-induced graft failure and cirrhosis, ${ }^{35-37}$ and other studies showing no significant association. ${ }^{38}$

\section{Intrinsic donor factors}

A number of donor factors have also been linked to HCV recurrence. Advanced donor age was observed to accelerate the progression of fibrosis in the transplanted liver, ${ }^{28,32,36,39}$ and the increasing age of donors was associated with a decrease in survival of HCV transplant recipients. ${ }^{39-41}$

The condition of the donor graft has an impact on HCV recurrence; the presence of donor graft steatosis is associated with earlier and more severe recurrence of HCV. ${ }^{42,43}$ Ischemia-reperfusion injury could also play a role, with both warm and cold ischemia times being implicated in HCV recurrence, although these findings are not consistent. ${ }^{28,39,44}$ The risk of HCV progression has not been linked to the type of donation, with no difference in risk between living donor liver transplants and deceased donor transplants. ${ }^{45}$

\section{Immunosuppression}

Immunosuppression post-liver transplantation is unavoidable and has been associated with increased disease severity in $\mathrm{HCV}$ recurrence. ${ }^{46}$ Berenguer et al. not only demonstrated that stronger immunosuppression was linked to worse outcome in recurrent $\mathrm{HCV}_{1}^{40}$ but that avoidance of potent immunosuppression yielded better patient outcome. ${ }^{47}$

Two of the most commonly used immunosuppressants in liver transplant patients are the calcineurin inhibitors (CNI) cyclosporine and tacrolimus. Numerous studies have investigated outcomes post-liver transplant between these two drugs. In the general liver transplant population, the use of tacrolimus is associated with significantly reduced rates of death, graft loss, acute rejection, and steroid-resistant rejection. ${ }^{48}$ However, multiple studies and a recent metaanalysis have demonstrated no correlation between the type of CNI used and the risk of HCV recurrence. ${ }^{49-52}$ Corticosteroid use also plays an important role in HCV recurrence. Treatment of acute cellular rejection with multiple boluses of corticosteroids as well as rapid tapering of steroids have both been linked to recurrent disease. ${ }^{19,53}$ Reduced progression of recurrent $\mathrm{HCV}$ and better patient outcomes were demonstrated with the use of slow tapering steroid regimens. ${ }^{47,54}$

\section{Treatment of HCV post-liver transplant}

Successful pretransplantation clearance of HCV-RNA has been shown to prevent recurrence of HCV but has previously been limited by side effects and low success rates. ${ }^{55,56}$ The advent of new, highly efficacious treatments for HCV has allowed for clearance of HCV with relatively low side effect profiles, and pretransplantation treatment of HCV will continue to play an important role in the prevention of recurrent $\mathrm{HCV}^{57}$ However, successful pretransplant treatment of $\mathrm{HCV}$ precludes the use of an $\mathrm{HCV}$-infected allograft, and numerous studies have demonstrated equivalent outcomes using HCV infected donors. ${ }^{58-61} \mathrm{HCV}$ positive donors represent an important source of transplanted allografts, with $23 \%$ of HCV related liver transplants receiving allografts from HCV positive donors. ${ }^{62}$ As long as donor livers continue to be scarce, post-transplant HCV is likely to remain a relevant clinical entity despite improved treatments. Two strategies exist for the treatment of HCV post-transplant: pre-emptive treatment of $\mathrm{HCV}$ before graft damage occurs and treatment of established recurrent $\mathrm{HCV}$ after histological evidence of significant fibrosis.

Until recently, the standard of care for treatment of recurrent HCV was combination therapy with IFN or pegylated IFN (PEG-IFN) and ribavirin (RBV). Dual therapy with these agents improved both patient and graft survival; ${ }^{63}$ but treatment carried a high rate of side effects, with SVR rates of only approximately $30 \%$. Significant side effects were common and led to premature discontinuation of therapy in another $30 \%$, mainly attributable to anemias, cytopenias, neuropsychiatric episodes, thyroid abnormality, poor tolerability, and rejection. Dose reductions due to anemias and other cytopenias were also commonly required. ${ }^{64-66}$ Pre-emptive treatment of acute recurrent HCV with IFN and RBV has been disappointing, with SVR rates much lower than those observed in treatment of nontransplanted patients with acute HCV infection. Studies have shown an SVR of only $10-25 \%$ in the transplant population compared with $90 \%$ in the nontransplant population. As with all patients treated with IFN 
and RBV post-transplant, there was a high rate of side effects. ${ }^{67,68}$

\section{New treatments}

The last few years has seen the introduction of Direct Acting Antivirals (DAAs), with treatments containing telaprevir and boceprevir approved in 2011, sofosbuvir and simeprevir in 2013, and, more recently, daclatasvir, ledipasvir, ombitasvir, paritaprevir, and dasabuvir. American Association for the Study of Liver Diseases (AASLD) and European Association for the Study of the Liver (EASL) recommendations for the treatment of recurrent HCV are summarized in Table 1, and Table 2 summarizes important recent studies on the treatment of recurrent $\mathrm{HCV}$ with DAAs.

\section{First generation DAAs}

Boseprevir and telaprevir are protease inhibitors that bind $\mathrm{HCV}$ nonstructural 3 (NS3) active site. In the post-transplant setting, combined with PEG-IFN and RBV, both drugs have been shown to be more effective than PEG-IFN/RBV dual therapy, with SVRs of $20-71 \% .^{69-72}$ However, as with the pretransplant population, the use of boseprevir and telaprevir is severely limited by their side effect profile. Especially significant side effects include severe cytopenias, with considerably more than half of all patients requiring the use of erythropoietin or packed red blood cell transfusions to treat severe anemia. ${ }^{69,71,73}$ These drugs frequently interact with immunosuppressive agents, such as cyclosporine and tacrolimus, requiring careful monitoring of trough levels and dose adjustment. ${ }^{69,71,73-77}$ Renal function is another concern in patients on triple therapy with boseprevir or telaprevir, with approximately $5 \%$ of patients developing renal impairment. ${ }^{78}$ These drugs are not commonly used in general practice.

\section{Second generation DAAs}

Simeprevir (Olysio ${ }^{\circledR}$ ) is a once daily HCV NS3/4A protease inhibitor that was initially introduced as a triple therapy with RBV and PEG-IFN. Quantitative Ultrasound Ezetimibe and Simvastatin Trial (QUEST)-1 and QUEST-2 demonstrated the superior efficacy of simeprevir triple therapy over PEG-IFN with RBV in treatment naive HCV genotype 1 patients, achieving an SVR 12 of $80 \%$ and $81 \%$, respectively. ${ }^{79,80}$ With the exception of one very small trial, simeprevir triple therapy has not been studied in the post-transplant or recurrent HCV population. ${ }^{81}$ The use of simeprevir triple therapy is limited by the Q80K (GIn80Lys) polymorphism, which is an NS3 polymorphism that reduces simeprevir's activity against HCV genotype 1a. In QUEST-1, patients with HCV genotype 1a with the Q80K polymorphism gained no benefit with the addition of simeprevir to PEG-IFN and RBV therapy when compared to placebo. ${ }^{79}$ There were no specific contraindications to simeprevir, and commonly encountered side effects include rash development (28\%), nausea (20\%), pruritus (20\%), myalgia $(16 \%)$, and dyspnea (12\%). Simeprevir has a number of clinically significant drug interactions, importantly with antiretrovirals used in HIV therapy, cyclosporine, and sirolimus. ${ }^{82}$

Sofosbuvir (Sovaldi ${ }^{\circledR}$ ) is an HCV nucleotide analogue NS5B polymerase inhibitor, and combination therapies containing sofosbuvir have now become the standard of care in HCV in the USA. ${ }^{10}$ Data from a compassionate use program using a combination of sofosbuvir and RBV in 103 patients with severe recurrent HCV yielded an SVR 12 of $59 \%$ when considering all patients and $73 \%$ in those with early recurrence. ${ }^{83}$ Charlton et al. studied sofosbuvir and RBV dual therapy in 40 patients with recurrent HCV in a multicenter, open label study and demonstrated an SVR 12 of $70 \%$. Anemia was seen in $20 \%$ patients, with fatigue (30\%), diarrhea (28\%), and headache $(25 \%)$ being the most common reported side effects. ${ }^{84}$ There have been several reports of the successful use of sofosbuvir and RBV with or without PEG-IFN to treat $\mathrm{FCH} .{ }^{83,85-87}$

Overall the side effect profile of the sofosbuvir/RBV combination is considerably better when compared to that of telaprevir and boseprevir triple therapy. ${ }^{84}$ In addition, in a study of healthy volunteers, sofosbuvir was not associated with significant changes in the level of cyclosporine or tacrolimus. ${ }^{88}$ The recently updated 2014 guidelines produced by AASLD and the Infectious Disease Society of America (IDSA) recommend sofosbuvir and RBV dual therapy for treatment naive patients with genotype 2 or 3 recurrent HCV. EASL

Table 1. Summary of AASLD/IDSA and EASL guidelines for management of post-transplant HCV

\begin{tabular}{|c|c|c|}
\hline Genotype & AASLD/IDSA & EASL \\
\hline \multirow[t]{4}{*}{1} & Ledipasvir + sofosbuvir + ribavirin for 12 weeks & Sofosbuvir + daclatasvir $+/-$ ribavirin for $12-24$ weeks \\
\hline & $\begin{array}{l}\text { Ledipasvir + sofosbuvir for } 24 \text { weeks (alternate } \\
\text { regimen if ribavirin intolerant or ineligible) }\end{array}$ & $\begin{array}{l}\text { Sofosbuvir }+ \text { simeprevir }+/- \text { ribavirin for } 12 \text { weeks } \\
\text { (alternate regimen) }\end{array}$ \\
\hline & $\begin{array}{l}\text { Sofosbuvir }+ \text { simeprevir }+/- \text { ribavirin for } 12 \text { weeks } \\
\text { (alternate regimen) }\end{array}$ & - \\
\hline & $\begin{array}{l}\text { Paritaprevir }+ \text { ritonavir }+ \text { ombitasvir }+ \text { dasabuvir for } \\
24 \text { weeks (alternate regimen) }\end{array}$ & - \\
\hline 2 & Sofosbuvir + ribavirin for 24 weeks & Sofosbuvir + ribavirin for $12-24$ weeks \\
\hline 3 & Sofosbuvir + ribavirin for 24 weeks & Sofosbuvir + daclatasvir +/- ribavirin for $12-24$ weeks \\
\hline \multirow[t]{2}{*}{4} & Ledipasvir + sofosbuvir + ribavirin for 12 weeks & Sofosbuvir + daclatasvir $+/-$ ribavirin for $12-24$ weeks \\
\hline & $\begin{array}{l}\text { Ledipasvir }+ \text { sofosbuvir for } 24 \text { weeks (alternate } \\
\text { regimen if ribavirin intolerant or ineligible) }\end{array}$ & $\begin{array}{l}\text { Sofosbuvir }+ \text { simeprevir }+/- \text { ribavirin for } 12 \text { weeks } \\
\text { (alternate regimen) }\end{array}$ \\
\hline 5 & - & Sofosbuvir + daclatasvir $+/-$ ribavirin for $12-24$ weeks \\
\hline 6 & - & Sofosbuvir + daclatasvir $+/-$ ribavirin for $12-24$ weeks \\
\hline
\end{tabular}


Mitchell O. et al: Management of hepatitis C post-liver transplantation






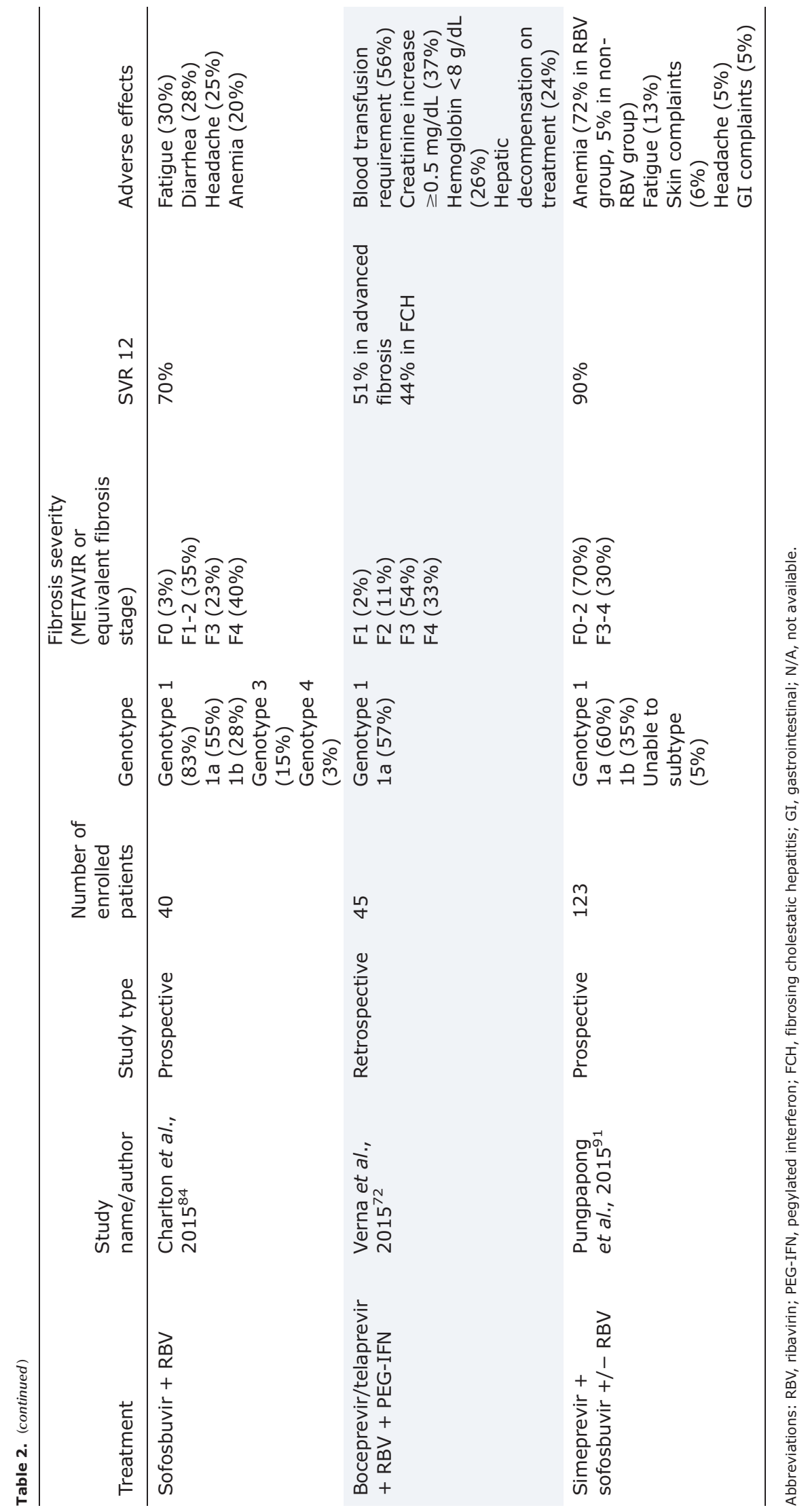


currently recommends sofosbuvir and RBV only for the treatment of recurrent genotype $2 \mathrm{HCV}^{9,10}$

Sofosbuvir is renally excreted and is not recommended in patients with creatinine clearance below $30 \mathrm{~mL} / \mathrm{min}$ or for those requiring hemodialysis or peritoneal dialysis due to a lack of studies in the area. NCT01958281 is a Phase-2 clinical trial that is currently recruiting and will investigate the safety of sofosbuvir with RBV in the treatment of patients with renal failure and HCV genotype 1 or 3 infection. ${ }^{89}$

Simeprevir and sofosbuvir dual therapy was studied in 167 treatment naive patients with HCV genotype 1 infection in the Combination Of SiMeprevir and sOfosbuvir in HCV genotype 1 infected patientS (COSMOS) trial. SVR 12 was achieved in $92 \%$ of patients, with the most common side effects being fatigue $(31 \%)$, headache $(20 \%)$, and nausea (16\%). In addition, the presence of the Q80K polymorphism did not have a significant detrimental effect on SVR. ${ }^{90}$ The efficacy of this combination has also been demonstrated in the post-transplant setting: Pungpapong and colleagues demonstrated that treatment with simeprevir and sofosbuvir with or without RBV was well tolerated and observed an SVR 12 of $90 \%$ in 123 patients with recurrent genotype $1 \mathrm{HCV}$. However, SVR 12 rates were lower in patients with advanced fibrosis and HCV genotype $1 \mathrm{a}$ (71\% in METAVIR F3-4 and $91 \%$ in F0-F2). ${ }^{91}$ The AASLD and IDSA have recommended this combination (with or without RBV) as an option for the first line treatment of recurrent $\mathrm{HCV}$ in treatment naive patients with HCV genotype $1 .{ }^{10}$ EASL extended this recommendation to include patients with genotype $4 .{ }^{9}$ The Phase-2 GALAXY study is currently recruiting and will investigate the efficacy and safety of sofosbuvir and simeprevir dual therapy with or without RBV post-liver transplant. ${ }^{92}$

\section{Third generation DAAs}

Daclatasvir (Daklinza) is an HCV NS5A inhibitor that is coadministered with sofosbuvir with or without RBV. In the pretransplant population, Sulkowski et al. studied daclatasvir plus sofosbuvir in 211 patients with HCV genotype 1, 2 or 3 . The SVR 12 was $98 \%$ and, like the other new DAAs, the side effect profile was favorable. The most common side effects were fatigue $(29-50 \%)$, headache $(16-38 \%)$, and nausea $(10-31 \%) .{ }^{93}$ Pellicelli et al. studied daclatasvir and sofosbuvir with or without RBV in 12 post-liver transplant patients (including three patients with $\mathrm{FCH}$ ) in a compassionate use program. They found that although the combination was very effective in clearing HCV infection, mortality was still high, probably due to the severity of underlying liver disease in the patient group studied. Importantly, they also found that no dose adjustment of the CNIs was required. ${ }^{94}$ ALLY-1 is an ongoing Phase-3 trial that is investigating daclatasvir, sofosbuvir, and RBV treatment in recurrent HCV. ${ }^{95}$ EASL recommends daclatasvir with sofosbuvir with or without RBV as treatment for recurrent HCV genotypes $1,3,4,5$ or $6,{ }^{9}$ but daclatasvir is not currently licensed in the USA.

Ledipasvir is an HCV 5S5A inhibitor that is prescribed in combination with sofosbuvir as a dual therapy (Harvoni ${ }^{\circledR}$ ). In the nontransplant population, the ION 1-3 trials showed SVR rates of $>96 \%$ with significantly reduced rates of side effects. The most common side effects were fatigue $(18 \%)$, headache $(17 \%)$, and nausea (9\%). ${ }^{96-98}$ Triple therapy with ledipasvir, sofosbuvir, and RBV has shown promise in the treatment of patients who have failed prior treatment with sofosbuvir-based regimens, with an SVR 12 of $98 \%$ in 51 patients, ${ }^{99}$ but there are no studies yet in the post-liver transplant population. Gilead announced results of the SOLAR-1 study at the 65th Annual Meeting of the AASLD. It was a Phase-2, open label study of 223 patients with recurrent HCV (genotypes 1 and 4) post-liver transplant who were treated with ledipasvir, sofosbuvir and RBV. In cirrhotic, noncirrhotic, and decompensated patients, SVR 12 rates were $96 \%, 98 \%$, and $81 \%$; and SVR 24 rates were $98 \%, 96 \%$, and $81 \%$ respectively. ${ }^{100}$ Ledipasvir plus sofosbuvir with or without RBV has recently been recommended by the AASLD as treatment for patients with genotype 1 or 4 recurrent HCV. ${ }^{10}$

The combination of ombitasvir, paritaprevir (ABT-450), dasabuvir, and ritonavir (viekira pak ${ }^{\mathrm{TM}}$ ) with RBV was studied in the CORAL-1 trial, which included 34 liver transplant patients with mild recurrent HCV. The SVR was $97 \%$, and although adverse effects of medication were common, the majority of these were classed as mild or moderate in severity. The most commonly reported side effects were fatigue $(50 \%)$, headache $(44 \%)$, cough $(32 \%)$, and anemia $(29 \%) .{ }^{101}$ This combination of drugs has a wide range of drug interactions, notably drugs that are dependent on cytochrome P3A (CYP3A), CYP3A, or CYP2C8 inducers and CYP2C8 inhibitors. Use of these drugs in the post-transplant patient also requires close monitoring of cyclosporine and tacrolimus levels. ${ }^{102}$ Ombitasvir, paritaprevir, dasabuvir, and ritonavir quadruple therapy is currently recommended by the AASLD as an alternate treatment option in recurrent HCV genotype $1 .{ }^{10}$

\section{Conclusions}

Due to the low success rates and high incidence of significant side effects seen with older HCV therapies, pre-emptive HCV therapy has been avoided; and treatment of recurrent HCV has historically been delayed until the development of significant damage on liver biopsy. ${ }^{9,16}$ The introduction of new DAAs reopens the discussion about the theoretical benefit of treating HCV before the development of significant liver allograft damage, and the optimal time for treatment of recurrent $\mathrm{HCV}$ has yet to be identified. While pretransplant eradication will continue to play a critical role in the prevention of recurrent $\mathrm{HCV}$, the advent of new drugs that achieve excellent rates of SVR with a low side effect profile in a group of patients who are notoriously difficult to treat heralds a turning point in the management of recurrent HCV.

\section{Acknowledgments}

This project is supported by the research grant from BMS.

\section{Conflict of interest}

Dr. Ahmet Gurakar is a consultant for Gilead.

\section{Author contributions}

Review of the literature and writing of the manuscript (OM), review of the literature and final editing of the manuscript (AG). 


\section{References}

1. Chak E, Talal AH, Sherman KE, Schiff ER, Saab S. Hepatitis $C$ virus infection in USA: an estimate of true prevalence. Liver Int 2011;31:1090-1101. doi: 10. $1111 / j .1478-3231.2011 .02494 . x$

2. Ly KN, Xing J, Klevens RM, Jiles RB, Ward JW, Holmberg SD. The increasing burden of mortality from viral hepatitis in the United States between 1999 and 2007. Ann Intern Med 2012;156:271-278. doi: 10.7326/0003-4819156-4-201202210-00004.

3. Hassan MM, Frome A, Patt YZ, El-Serag HB. Rising prevalence of hepatitis C virus infection among patients recently diagnosed with hepatocellular carcinoma in the United States. J Clin Gastroenterol 2002;35:266-269.

4. Roberts MS, Angus DC, Bryce CL, Valenta Z, Weissfeld L. Survival after liver transplantation in the United States: a disease-specific analysis of the UNOS database. Liver Transpl 2004;10:886-897.

5. Perz JF, Armstrong GL, Farrington LA, Hutin YJ, Bell BP. The contributions of hepatitis $B$ virus and hepatitis $C$ virus infections to cirrhosis and primary liver cancer worldwide. J Hepatol 2006;45:529-538.

6. Kim WR, Smith JM, Skeans MA, Schladt DP, Schnitzler MA, Edwards EB, et al. OPTN/SRTR 2012 Annual Data Report: liver. Am J Transplant 2014;14:6996. doi: 10.1111/ajt.12581.

7. Razavi H, Elkhoury AC, Elbasha E, Estes C, Pasini K, Poynard T, et al. Chronic hepatitis $\mathrm{C}$ virus (HCV) disease burden and cost in the United States. Hepatology 2013;57:2164-2170. doi: 10.1002/hep.26218.

8. Reau NS, Jensen DM. Sticker shock and the price of new therapies for hepatitis C: is it worth it? Hepatology 2014;59:1246-1249. doi: 10.1002/hep. 27039.

9. http://files.easl.eu/easl-recommendations-on-treatment-of-hepatitis-C.pdf, accessed February 2015

10. http://www.hcvguidelines.org/, accessed February 2015.

11. Pelletier SJ, Raymond DP, Crabtree TD, Berg CL, Iezzoni JC, Hahn YS, et al. Hepatitis $C$-induced hepatic allograft injury is associated with a pretransplantation elevated viral replication rate. Hepatology 2000;32:418-426. doi:10. 1053/jhep.2000.9408.

12. Herrmann E, Zeuzem S, Sarrazin C, Hinrichsen H, Benhamou Y, Manns MP, et al. Viral kinetics in patients with chronic hepatitis $C$ treated with the serine protease inhibitor BILN 2061. Antivir Ther 2006;11:371-376.

13. Gane EJ, Portmann BC, Naoumov NV, Smith HM, Underhill JA, Donaldson PT, et al. Long-term outcome of hepatitis $C$ infection after liver transplantation. N Engl J Med 1996;334:815-820. doi: 10.1056/NEJM199603283341302.

14. Gane $\mathrm{E}$. The natural history and outcome of liver transplantation in hepatitis C virus-infected recipients. Liver Transpl 2003;9:S28-S34. doi:10.1053/jlts. 2003.50248.

15. Rodriguez-Luna $\mathrm{H}$, Vargas HE. Management of hepatitis $\mathrm{C}$ virus infection in the setting of liver transplantation. Liver Transpl 2005;11:479-89. doi:10. 3748/wjg.v21.i2.408.

16. Wiesner RH, Sorrell M, Villamil F. International Liver Transplantation Society Expert, Report of the first International Liver Transplantation Society expert panel consensus conference on liver transplantation and hepatitis C. Liver Transpl 2003;9:S1-S9.doi:10.1053/jlts.2003.50268.

17. Feray C, Caccamo L, Alexander GJ, Ducot B, Gugenheim J, Casanovas T, et al. European collaborative study on factors influencing outcome after liver transplantation for hepatitis C. European Concerted Action on Viral Hepatitis (EUROHEP) Group. Gastroenterology 1999;117:619-625.

18. Berenguer M, Prieto M, Rayon JM, Mora J, Pastor M, Ortiz V, et al. Natural history of clinically compensated hepatitis $C$ virus-related graft cirrhosis after liver transplantation. Hepatology 2000;32:852-858. doi:10.1053/jhep. 2000.17924.

19. Berenguer M, Ferrell L, Watson J, Prieto M, Kim M, Rayon M, et al. HCVrelated fibrosis progression following liver transplantation: increase in recent years. J Hepatol 2000; 32:673-684. doi:10.1016/S0168-8278(00)80231-7.

20. Berenguer M, Rayon JM, Prieto M, Aguilera V, Nicolas D, Ortiz V, et al. Are posttransplantation protocol liver biopsies useful in the long term? Liver Transpl 2001;7:790-796. doi:10/S1527646501670618.

21. Graziadei IW, Zoller HM, Schloegl A, Nachbaur K, Pfeiffer KP, Mark W, et al. Early viral load and recipient interleukin-28B rs12979860 genotype are predictors of the progression of hepatitis $\mathrm{C}$ after liver transplantation. Liver Transpl 2012;18:671-679. doi: 10.1002/It.23402.

22. Pelletier SJ, Schaubel DE, Punch DJ, Wolfe RA, Port FK, Merion RM. Hepatitis $C$ is a risk factor for death after liver retransplantation. Liver Transpl 2005 ; 11:434-440. doi:10.1002/It.20342.

23. Ghabril M, Dickson R, Wiesner R. Improving outcomes of liver retransplantation: an analysis of trends and the impact of Hepatitis C infection. Am J Transplant 2008;8:404-411. doi: 10.1111/j.1600-6143.2007.02082.x.

24. Berenguer $M$, Aguilera $V$, Prieto $M$, San Juan $F$, Rayon JM, Benlloch $S$, et al. Effect of calcineurin inhibitors on survival and histologic disease severity in HCV-infected liver transplant recipients. Liver Transpl 2006;12:762-767. doi:10.1002/lt.20655.
25. Gane EJ. The natural history of recurrent hepatitis $C$ and what influences this. Liver Transpl 2008;14:S36-S44. doi: 10.1002/It.21646.

26. Charlton M, Seaberg E, Wiesner R, Everhart J, Zetterman R, Lake J, et al. Predictors of patient and graft survival following liver transplantation for hepatitis C. Hepatology 1998;28:823-830. doi:10.1002/hep.510280333.

27. Blasco A, Forns X, Carrion JA, Garcia-Pagan JC, Gilabert R, Rimola A, et al. Hepatic venous pressure gradient identifies patients at risk of severe hepatitis C recurrence after liver transplantation. Hepatology 2006;43: 492-499. doi:10.1002/hep.21090.

28. Nagai S, Yoshida A, Kohno K, Altshuler D, Nakamura M, Brown KA, et al. Peritransplant absolute lymphocyte count as a predictive factor for advanced recurrence of hepatitis C after liver transplantation. Hepatology 2014;59: 35-45. doi: 10.1002/hep.26536.

29. Charlton MR, Thompson A, Veldt BJ, Watt K, Tillmann H, Poterucha JJ, et al. Interleukin-28B polymorphisms are associated with histological recurrence and treatment response following liver transplantation in patients with hepatitis C virus infection. Hepatology 2011;53:317-324. doi: 10.1002/hep. 24074.

30. Cisneros E, Banos I, Citores MJ, Duca A, Salas C, Noblejas A, et al. Increased risk of severe hepatitis $C$ virus recurrence after liver transplantation in patients with a T allele of IL28B rs12979860. Transplantation 2012;94: $275-280$.

31. Forman LM, Lewis JD, Berlin JA, Feldman HI, Lucey MR. The association between hepatitis $\mathrm{C}$ infection and survival after orthotopic liver transplantation. Gastroenterology 2002;122:889-896.

32. Belli LS, Burroughs AK, Burra P, Alberti AB, Samonakis D, Camma C, et al. Liver transplantation for HCV cirrhosis: improved survival in recent years and increased severity of recurrent disease in female recipients: results of a long term retrospective study. Liver Transpl 2007;13:733-740. doi:10.1002/It. 21093.

33. Layden JE, Cotler S, Brown KA, Lucey MR, Te HS, Eswaran S, et al. Racial differences in fibrosis progression after HCV-related liver transplantation. Transplantation 2012;94:178-184. doi: 10.1097/TP.0b013e318253f7fa.

34. Verna EC, Valadao R, Farrand E, Pichardo EM, Lai JC, Terrault NA, et al. Effects of ethnicity and socioeconomic status on survival and severity of fibrosis in liver transplant recipients with hepatitis C virus. Liver Transpl 2012;18:461467. doi: 10.1002/lt.23376.

35. Rosen HR, Chou S, Corless CL, Gretch DR, Flora KD, Boudousquie A, et al. Cytomegalovirus viremia: risk factor for allograft cirrhosis after liver transplantation for hepatitis C. Transplantation 1997;64:721-726.

36. Burak KW, Kremers WK, Batts KP, Wiesner RH, Rosen CB, Razonable RR, et al. Impact of cytomegalovirus infection, year of transplantation, and donor age on outcomes after liver transplantation for hepatitis C. Liver Transpl 2002;8: 362-369.

37. Bosch W, Heckman MG, Pungpapong S, Diehl NN, Shalev JA, Hellinger WC. Association of cytomegalovirus infection and disease with recurrent hepatitis C after liver transplantation. Transplantation 2012;93:723-728. doi: 10. 1097/TP.0b013e3182472876.

38. Humar A, Kumar D, Raboud J, Caliendo AM, Moussa G, Levy G, et al. Interactions between cytomegalovirus, human herpesvirus- 6 , and the recurrence of hepatitis C after liver transplantation. Am J Transplant 2002;2:461-466.

39. Wali M, Harrison RF, Gow PJ, Mutimer D. Advancing donor liver age and rapid fibrosis progression following transplantation for hepatitis C. Gut 2002;51: 248-252. doi:10.1136/gut.51.2.248.

40. Berenguer M, Prieto M, San Juan F, Rayon JM, Martinez F, Carrasco D, et al. Contribution of donor age to the recent decrease in patient survival among HCV-infected liver transplant recipients. Hepatology 2002;36:202-210.

41. Berenguer M. Host and donor risk factors before and after liver transplantation that impact HCV recurrence. Liver Transpl 2003;9:S44-S47.

42. Briceno J, Ciria R, Pleguezuelo M, de la Mata M, Muntane J, Naranjo A, et al. Impact of donor graft steatosis on overall outcome and viral recurrence after liver transplantation for hepatitis C virus cirrhosis. Liver Transpl 2009;15:3748. doi: $10.1002 /$ It.21566.

43. Subramanian V, Seetharam AB, Vachharajani N, Tiriveedhi V, Angaswamy N, Ramachandran $\mathrm{S}$, et al. Donor graft steatosis influences immunity to hepatitis $C$ virus and allograft outcome after liver transplantation. Transplantation 2011;92:1259-1268. doi: 10.1097/TP.0b013e318235a1ab.

44. Baron PW, Sindram D, Higdon D, Howell DN, Gottfried MR, Tuttle-Newhall JE, et al. Prolonged rewarming time during allograft implantation predisposes to recurrent hepatitis $C$ infection after liver transplantation. Liver Transpl 2000; 6:407-412.

45. Terrault NA, Stravitz RT, Lok AS, Everson GT, Brown RS, Kulik LM, et al. Hepatitis $C$ disease severity in living versus deceased donor liver transplant recipients: an extended observation study. Hepatology 2014;59:13111319. doi: 10.1002/hep.26920.

46. Papatheodoridis GV, Davies S, Dhillon AP, Teixeira R, Goulis J, Davidson B, et al. The role of different immunosuppression in the long-term histological outcome of HCV reinfection after liver transplantation for HCV cirrhosis. Transplantation $2001 ; 72: 412-418$ 
47. Berenguer $\mathrm{M}$, Aguilera $\mathrm{V}$, Prieto $\mathrm{M}$, San Juan $\mathrm{F}$, Rayon JM, Benlloch $\mathrm{S}$, et al. Significant improvement in the outcome of HCV-infected transplant recipients by avoiding rapid steroid tapering and potent induction immunosuppression. J Hepatol 2006;44:717-722.

48. McAlister VC, Haddad E, Renouf E, Malthaner RA, Kjaer MS, Gluud LL. Cyclosporin versus tacrolimus as primary immunosuppressant after liver transplantation: a meta-analysis. Am J Transplant 2006;6:1578-1585. doi: 10. 1111/j.1600-6143.2006.01360.x.

49. Martin P, Busuttil RW, Goldstein RM, Crippin JS, Klintmalm GB, Fitzsimmons $W E$, et al. Impact of tacrolimus versus cyclosporine in hepatitis $C$ virusinfected liver transplant recipients on recurrent hepatitis: a prospective, randomized trial. Liver Transpl 2004;10:1258-1262.

50. Levy G, Grazi GL, Sanjuan F, Wu Y, Muhlbacher F, Samuel D, et al. 12-month follow-up analysis of a multicenter, randomized, prospective trial in de novo liver transplant recipients. (LIS2T) comparing cyclosporine microemulsion (C2 monitoring) and tacrolimus Liver Transpl 2006;12:1464-1472. doi: 10.1002/It.20802.

51. Berenguer M, Aguilera V, San Juan F, Benlloch S, Rubin A, Lopez-Andujar R, et al. Effect of calcineurin inhibitors in the outcome of liver transplantation in hepatitis C virus-positive recipients. Transplantation 2010;90:1204-1209. doi: 10.1097/TP.0b013e3181fa93fa.

52. Liu Z, Chen $Y$, Tao $R, X v$ J, Meng J, Yong $X$. Tacrolimus-based versus cyclosporine-based immunosuppression in hepatitis $C$ virus-infected patients after liver transplantation: a meta-analysis and systematic review. PLoS One 2014;9:e107057. doi: 10.1371/journal.pone.0107057.

53. Neumann UP, Berg T, Bahra M, Puhl G, Guckelberger O, Langrehr JM, et al. Long-term outcome of liver transplants for chronic hepatitis C: a 10-year follow-up. Transplantation 2004;77:226-231.

54. Vivarelli M, Burra P, La Barba G, Canova D, Senzolo M, Cucchetti A, et al. Influence of steroids on HCV recurrence after liver transplantation: A prospective study. J Hepatol 2007;47:793-798. doi: 10.1016/j.jhep.2007.07. 023.

55. Everson GT. Treatment of patients with hepatitis $C$ virus on the waiting list. Liver Transpl 2003;9:S90-S94. doi:10.1053/jlts.2003.50247.

56. Forns X, Garcia-Retortillo M, Serrano T, Feliu A, Suarez F, de la Mata M, et al. Antiviral therapy of patients with decompensated cirrhosis to prevent recurrence of hepatitis C after liver transplantation. J Hepatol 2003;39:389-396. doi: 10.1016/S0168-8278(03)00310-6.

57. Curry MP, Forns X, Chung RT, Terrault NA, Brown R, Fenkel JM, et al. Sofosbuvir and ribavirin prevent recurrence of $\mathrm{HCV}$ infection after liver transplantation: an open-label study. Gastroenterology 2015;148:100-107.e1. doi: 10.1053/j.gastro.2014.09.023

58. Testa G, Goldstein RM, Netto G, Abbasoglu O, Brooks BK, Levy MF, et al. Long-term outcome of patients transplanted with livers from hepatitis Cpositive donors. Transplantation 1998;65:925-929.

59. Ghobrial RM, Steadman R, Gornbein J, Lassman C, Holt CD, Chen P, et al. A 10-year experience of liver transplantation for hepatitis $C$ : analysis of factors determining outcome in over 500 patients. Ann Surg 2001;234:384-393. discussion 393-394

60. Marroquin CE, Marino G, Kuo PC, Plotkin JS, Rustgi VK, Lu AD, et al. Transplantation of hepatitis C-positive livers in hepatitis C-positive patients is equivalent to transplanting hepatitis C-negative livers. Liver Transpl 2001; 7:762-768. doi:10/S1527646501360768.

61. Ballarin R, Cucchetti A, Spaggiari M, Montalti R, Di Benedetto F, Nadalin S, et al. Long-term follow-up and outcome of liver transplantation from antihepatitis C virus-positive donors: a European multicentric case-control study. Transplantation 2011;91:1265-1272. doi: 10.1097/TP. 0b013e318219eb8f

62. Ofosu A, Durand C, Alqahtani S, Cameron A, Sulkowski M, Gurakar A. Implications of Treating Hepatitis $C$ Virus Infection in Individuals Awaiting Liver Transplantation. Am J Gastroenterol 2014;109:S162.

63. Veldt BJ, Poterucha JJ, Watt KD, Wiesner RH, Hay JE, Kremers WK, et al. Impact of pegylated interferon and ribavirin treatment on graft survival in liver transplant patients with recurrent hepatitis C infection. Am J Transplant 2008;8:2426-2433. doi: 10.1111/j.1600-6143.2008.02362.x.

64. Samuel D, Bizollon T, Feray C, Roche B, Ahmed SN, Lemonnier C, et al. Interferon-alpha $2 \mathrm{~b}$ plus ribavirin in patients with chronic hepatitis $\mathrm{C}$ after liver transplantation: a randomized study. Gastroenterology 2003;124:642650. doi: 10.1053/gast.2003.50095.

65. Berenguer M. Systematic review of the treatment of established recurrent hepatitis $\mathrm{C}$ with pegylated interferon in combination with ribavirin. J Hepatol 2008;49:274-287. doi: 10.1016/j.jhep.2008.05.002.

66. Guillouche P, Feray C. Systematic review: anti-viral therapy of recurrent hepatitis C after liver transplantation. Aliment Pharmacol Ther 2011;33:163174. doi: 10.1111/j.1365-2036.2010.04505.x.

67. Shergill AK, Khalili M, Straley S, Bollinger K, Roberts JP, Ascher NA, et al. Applicability, tolerability and efficacy of preemptive antiviral therapy in hepatitis C-infected patients undergoing liver transplantation. Am J Transplant 2005;5:118-124. doi:10.1111/j.1600-6143.2004.00648.x.
68. Bzowej N, Nelson DR, Terrault NA, Everson GT, Teng LL, Prabhakar A, et al. PHOENIX: A randomized controlled trial of peginterferon alfa-2a plus ribavirin as a prophylactic treatment after liver transplantation for hepatitis $C$ virus. Liver Transpl 2011;17:528-538. doi: 10.1002/lt.22271.

69. Burton JR Jr, O'Leary JG, Verna EC, Saxena V, Dodge JL, Stravitz RT, et al. A US multicenter study of hepatitis $C$ treatment of liver transplant recipients with protease-inhibitor triple therapy. J Hepatol 2014;61:508-514. doi: 10. 1016/j.jhep.2014.04.037.

70. Coilly A, Roche B, Dumortier J, Leroy V, Botta-Fridlund D, Radenne S, et al. Safety and efficacy of protease inhibitors to treat hepatitis $C$ after liver transplantation: a multicenter experience. J Hepatol 2014;60:78-86. doi: 10.1016/j.jhep.2013.08.018.

71. Saab S, Manne V, Bau S, Reynolds JA, Allen R, Goldstein L, et al. Boceprevir in liver transplant recipients. Liver Int 2015;35:192-197. doi: 10.1111/liv. 12548.

72. Verna EC, Saxena V, Burton JR Jr, O'Leary JG, Dodge JL, Stravitz RT, et al. Telaprevir- and Boceprevir-Based Triple Therapy for Hepatitis C in Liver Transplant Recipients With Advanced Recurrent Disease: A Multicenter Study. Transplantation 2015.

73. Pungpapong S, Aqel BA, Koning L, Murphy JL, Henry TM, Ryland KL, et al. Multicenter experience using telaprevir or boceprevir with peginterferon and ribavirin to treat hepatitis C genotype 1 after liver transplantation. Liver Transpl 2013:19:690-700. doi: 10.1002/lt.23669.

74. Garg V, van Heeswijk R, Lee JE, Alves K, Nadkarni P, Luo X. Effect of telaprevir on the pharmacokinetics of cyclosporine and tacrolimus. Hepatology 2011; 54:20-27. doi: 10.1002/hep.24443.

75. Coilly A, Furlan V, Roche B, Barau C, Noel C, Bonhomme-Faivre L, et al. Practical management of boceprevir and immunosuppressive therapy in liver transplant recipients with hepatitis $C$ virus recurrence. Antimicrob Agents Chemother 2012;56:5728-5734. doi: 10.1128/AAC.01151-12.

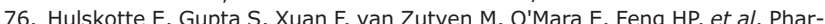
macokinetic interaction between the hepatitis $C$ virus protease inhibitor boceprevir and cyclosporine and tacrolimus in healthy volunteers. Hepatology 2012;56:1622-1630. doi: 10.1002/hep.25831.

77. Werner CR, Egetemeyr DP, Lauer UM, Nadalin S, Konigsrainer A, Malek NP, et al. Telaprevir-based triple therapy in liver transplant patients with hepatitis $C$ virus: a 12-week pilot study providing safety and efficacy data. Liver Transpl 2012;18:1464-1470. doi: 10.1002/It.23542.

78. Mauss $S$, Hueppe $D$, Alshuth $U$. Renal impairment is frequent in chronic hepatitis $C$ patients under triple therapy with telaprevir or boceprevir. Hepatology 2014;59:46-48. doi: 10.1002/hep.26730.

79. Jacobson IM, Dore GJ, Foster GR, Fried MW, Radu M, Rafalsky VV, et al. Simeprevir with pegylated interferon alfa 2a plus ribavirin in treatment-naive patients with chronic hepatitis C virus genotype 1 infection. (QUEST-1): a phase 3, randomised, double-blind, placebo-controlled trial. Lancet 2014; 384:403-413. doi: 10.1016/S0140-6736(14)60494-3.

80. Manns M, Marcellin P, Poordad F, de Araujo ES, Buti M, Horsmans Y, et al. Simeprevir with pegylated interferon alfa $2 \mathrm{a}$ or $2 \mathrm{~b}$ plus ribavirin in treatmentnaive patients with chronic hepatitis $C$ virus genotype 1 infection. (QUEST2): a randomised, double-blind, placebo-controlled phase 3 trial. Lancet 2014;384:414-426. doi: 10.1016/S0140-6736(14)60538-9.

81. Tanaka T, Sugawara Y, Akamatsu N, Kaneko J, Tamura S, Aoki T, et al. Use of simeprevir following pre-emptive pegylated interferon/ribavirin treatment for recurrent hepatitis $C$ in living donor liver transplant recipients: a 12-week pilot study. ] Hepatobiliary Pancreat Sci 2015;22:144-150. doi: 10. 1002/jhbp.171.

82. www.olysio.com, accessed February 2015

83. Forns X, Charlton M, Denning J, McHutchison JG, Symonds WT, Brainard D, et al. Sofosbuvir compassionate use program for patients with severe recurrent hepatitis C following liver transplantation. Hepatology 2014; Dec 29. doi: 10. 1002/hep. 27681.

84. Charlton M, Gane E, Manns MP, Brown RS Jr, Curry MP, Kwo PY, et al. Sofosbuvir and ribavirin for treatment of compensated recurrent hepatitis $C$ virus infection after liver transplantation. Gastroenterology 2015;148:108-117. doi: 10.1053/j.gastro.2014.10.001.

85. Borentain P, Colson P, Dhiver C, Gregoire E, Hardwigsen J, Danielle B-f, et al. Successful treatment with sofosbuvir of fibrosing cholestatic hepatitis $C$ after liver transplantation in HIV-HCV coinfected patient. Antivir Ther 2014;Aug 8. doi: $10.3851 /$ IMP2841.

86. Kim B, Trivedi A, Thung SN, Grewal P. Case report of successful treatment of fibrosing cholestatic hepatitis $C$ with sofosbuvir and ribavirin after liver transplantation. Semin Liver Dis 2014;34:108-112. doi: 10.1055/s-00341371084

87. Delabaudiere C, Lavayssiere L, Dorr G, Muscari F, Danjoux M, Sallusto F, et al. Successful treatment of fibrosing cholestatic hepatitis with pegylated interferon, ribavirin and sofosbuvir after a combined kidney-liver transplantation. Transpl Int 2015;28:255-258. doi: 10.1111/tri.12428.

88. Mathias A, Cornpropst M, Clemons D, Denning J, Symonds WT. No clinically significant pharmacokinetic drug-drug interactions between sofosbuvir (GS7977) and the immunosuppressants, cyclosporine A or tacrolimus in healthy 
volunteers (Abstract 1869), in 63rd Annual Meeting of the American Association for the Study of Liver Diseases (AASLD). 2012, Boston.

89. www.clinicaltrials.gov, accessed February 2015.

90. Lawitz E, Sulkowski MS, Ghalib R, Rodriguez-Torres M, Younossi ZM, Corregidor $A$, et al. Simeprevir plus sofosbuvir, with or without ribavirin, to treat chronic infection with hepatitis $C$ virus genotype 1 in non-responders to pegylated interferon and ribavirin and treatment-naive patients: the COSMOS randomised study. Lancet 2014;384:1756-1765. doi: 10.1016/S0140-6736 (14)61036-9.

91. Pungpapong S, Aqel B, Leise M, Werner KT, Murphy JL, Henry TM, et al. Multicenter experience using simeprevir and sofosbuvir with or without ribavirin to treat hepatitis C genotype 1 after liver transplant. Hepatology 2015. doi: 10. 1002/hep. 27770 .

92. ClinicalTrials.gov. An Efficacy and Safety Study of Simeprevir and Sofosbuvir With and Without Ribavirin in Participants With Recurrent Genotype 1 Hepatitis C Post-Orthotopic Liver Transplant (GALAXY), accessed February 2015.

93. Sulkowski MS, Gardiner DF, Rodriguez-Torres M, Reddy KR, Hassanein T, Jacobson I, et al. Daclatasvir plus sofosbuvir for previously treated or untreated chronic HCV infection. N Engl J Med 2014;370:211-221. doi: 10. 1056/NEJMoa1306218.

94. Pellicelli AM, Montalbano M, Lionetti R, Durand C, Ferenci P, D'Offizi G, et al. Sofosbuvir plus daclatasvir for post-transplant recurrent hepatitis $C$ : potent antiviral activity but no clinical benefit if treatment is given late. Dig Liver Dis 2014;46:923-927. doi: 10.1016/j.dld.2014.06.004.
95. ClinicalTrials.gov, Phase III Daclatasvir, Sofosbuvir, and Ribavirin in Cirrhotic Subjects and Subjects Post-liver Transplant (ALLY 1), accessed February 2015.

96. Afdhal N, Zeuzem S, Kwo P, Chojkier M, Gitlin N, Puoti M, et al. Ledipasvir and sofosbuvir for untreated HCV genotype 1 infection. N Engl J Med 2014;370: 1889-1898. doi: 10.1056/NEJMoa1402454.

97. Afdhal N, Reddy KR, Nelson DR, Lawitz E, Gordon SC, Schiff E, et al. Ledipasvir and sofosbuvir for previously treated HCV genotype 1 infection. N Engl J Med 2014;370:1483-1493. doi: 10.1056/NEJMoa1316366.

98. Kowdley KV, Gordon SC, Reddy KR, Rossaro L, Bernstein DE, Lawitz E, et al. Ledipasvir and sofosbuvir for 8 or 12 weeks for chronic HCV without cirrhosis. N Engl J Med 2014;370:1879-1888. doi: 10.1056/NEJMoa1402355.

99. Wiles D, Pockros PJ, Zhu Y, Yang JC, Pang PS, McHutchison J, et al. Retreatment of Patients Who Failed Prior Sofosbuvir-Based Regimens With All Ora Fixed-Dose Combination Ledipasvir/Sofosbuvir Plus Ribavirin for 12 Weeks, in 65th Annual Meeting of the American Association for the Study of Liver Diseases. 2014, Boston.

100. Reddy KR, Everson GT, Flamm SL, Denning JM, Arterburn S, Brandt-Sarif T, et al. Ledipasvir/Sofosbuvir with Ribavirin for the Treatment of HCV in Patients with Post-Transplant Recurrence: Preliminary Results of a Prospective, Multicenter Study, in 65th Meeting of the American Association for the Study of Liver Diseases. 2014, Boston.

101. Kwo PY, Mantry PS, Coakley E, Te HS, Vargas HE, Brown R, et al. An interferon-free antiviral regimen for HCV after liver transplantation. N Engl J Med 2014;371:2375-2382. doi: 10.1056/NEJMoa1408921.

102. www.rxabbvie.com, accessed February 2015. 